\title{
Complications of traditional and modern therapeutic salivary approaches
}

\author{
Complicanze degli approcci terapeutici tradizionali e moderni alle ghiandole \\ salivari \\ O. NAHLIELI \\ Oral and Maxillofacial Surgery Department Barzilai Medical Center, Ashkelon, Israel. Affiliated to the Faculty of \\ Medicine, Ben Gurion University of the Negev, Beer Sheva, Israel
}

\begin{abstract}
SUMMARY
The morbidity following traditional surgery of the salivary glands is well documented and includes postsurgical complications such as the Frey's syndrome, complete or partial facial nerve damage, facial scarring, greater auricular nerve numbness, sialocoeles and salivary fistula. The avulsion of the salivary duct, secondary strictures, gland swelling, salivary fistulas and perforations (false rout), traumatic ranulas, and the lingual nerve paraesthesia are the main endoscopy-related complications. In general, the rate of postsurgical complications after modern advanced minimally invasive surgical interventions is significantly lower compared with traditional surgery of the salivary glands. However, such comparisons cannot be performed because up-to-date traditional and minimally invasive surgical techniques are applied to different salivary disorders. Combinations of various minimally invasive techniques are also possible. There is no clear borderline between "traditional" and "modern" surgery of the salivary glands. It is appropriate to write about gradual replacement of old techniques with newer ones, and this process has no traffic lights.
\end{abstract}

KEY WORDS: Complications $\bullet$ Minimally invasive surgery $\bullet$ Salivary glands

\section{RIASSUNTO}

Le complicanze dopo chirurgia tradizionale delle ghiandole salivari sono notoriamente documentate in letteratura e comprendono: la sindrome di Frey, la paralisi parziale o completa del nervo facciale, le lesioni del nervo grande auricolare, lo scialocele, la fistola salivare e gli esiti cicatriziali a livello della cute del volto. Per contro, le principali complicanze secondarie ai trattamenti endoscopici risultano essere l'avulsione del dotto salivare, le stenosi secondarie, la tumefazione ghiandolare, le fistole salivari, le perforazioni da falsa strada, le ranule post- traumatiche e le parestesie del nervo linguale. In generale, le moderne tecniche di chirurgia minimamente invasiva mostrano un tasso di complicanze post-operatorie significativamente inferiore rispetto alla chirurgia tradizionale delle ghiandole salivari. Tuttavia, un confronto tra le due strategie chirurgiche non può svolgersi correttamente perché esse sono applicate a diversi ambiti patologici. La combinazione di più tecniche di chirurgia minimamente invasiva rende sfumata la linea di confine tra chirurgia "tradizionale" $e$ "moderna", risultando utile e necessaria una più dettagliata descrizione del progressivo abbandono delle tecniche tradizionali a favore delle nuove.

PAROLE CHIAVE: Complicanze $\bullet$ Chirurgia minimamente invasiva $\bullet$ Ghiandole salivari

Acta Otorhinolaryngol Ital 2017;37:142-147

\section{Introduction}

The removal of the salivary gland (parotidectomy, submandibular sialadenectomy, sublingual sialadenectomy) for benign or malignant tumour as well as non-neoplastic disease was a common procedure in the previous century. The morbidity following such traditional surgery is well documented and includes postsurgical complications such as postoperative partial or complete facial nerve damage, Frey's syndrome, facial scarring, greater auricular nerve numbness, sialocoeles, and salivary fistula. Taking both medical necessity and aesthetic sentiments into consideration, the need for minimally invasive approaches to the diseases of the salivary glands was well understood. A minimally invasive approach, however, is limited to non-neoplastic diseases, mainly sialolithiasis and ductal obstructions. A method for salivary gland calculus disintegration by shock waves was proposed already in the $1980 \mathrm{~s}^{12}$. Shock waves produced by a Dornier lithotripter are able to destruct large salivary stones, but no practitioner can be sure that all the fragments will be washed out from the gland by saliva.

Therefore, an endoscopic technique was attempted. This approach was developed in the 1990s parallel to further improvements in lithotripsy ${ }^{3-6}$. Sialoendoscopes with stone-extraction baskets or forceps and balloon catheters were developed for therapeutic purposes. While tumours of the salivary glands are not to be treated by minimally invasive surgery, obstructive sialadenitis, with or without sialolithiasis, strictures and kinks, is treatable by minimally invasive techniques. Therefore, the traditional surgical 
and the minimally invasive surgical approaches currently coexist. It might be easy to compare rates of postsurgical complications after these two types of operations, but there are at least two obstacles for such an analysis. First, today sialadenectomy and minimally invasive surgery are applied to different diseases of the glands. Most cases with sialolithiasis and ductal obstructions are treated by minimally invasive means, while tumours of the parotid submandibular or sublingual gland will be managed with various types of sialadenectomy. Second, both surgical approaches partially overlap and in some cases "videoassisted" or "endoscopically-assisted" traditional surgery is currently applied. Minimally invasive approaches, or "less aggressive surgery", for traditional parotidectomy suggest selective superficial lobe parotidectomy instead of superficial lobectomy. Combinations of various minimally invasive techniques are also possible. There is no clear borderline between "traditional" and "modern" surgery of the salivary glands. It is thus appropriate to write about gradual replacement of the old techniques with the new ones, and this process has no traffic lights.

All current surgical approaches to the salivary gland diseases can be classified in the following way:

- standard traditional surgery (i.e. parotidectomy, sialadenectomy);

- less aggressive traditional surgery (i.e. partial parotidectomy, extracapsular dissection);

- video-assisted/endsocopically assisted traditional surgery;

- transoral/intraoral surgical approaches;

- endsocopically assisted transoral/intraoral surgical approaches;

- $\quad$ the extracorporeal shock-wave lithotripsy (ESWL);

- a combination of ESWL with a sialoendoscopic approach;

- direct sialoendoscopic removal of stones via salivary ducts and/or endoscopic assistance techniques.

Postsurgical complication therefore can be classified into:

- surgical complications;

- endoscopy-related complications;

- ESWL-related complications.

\section{Surgical complications of traditional surgery}

Parotidectomy. Article titles such as "Parotidectomy: surgery in evolution" or "Evolution and changing trends in surgery for benign parotid tumours" clearly indicates the current situation in the salivary surgery and its gradual movement towards minimally invasive techniques ${ }^{78}$. Yet, benign and malignant tumours are to be operated traditionally. Such traditional surgical approaches include partial superficial parotidectomy, superficial parotidectomy with preparation of the facial nerve and total parotidectomy with or without preservation of the facial nerve (radical parotidectomy). Attempts to perform selective deep-lobe parotidectomy with preservation of the superficial lobe in benign cases were made in the $1990 \mathrm{~s}^{910}$. It was demonstrated, however, that temporary facial nerve dysfunction had a significantly higher incidence if tumours were located in the deep lobe of the gland ${ }^{11}$. At the same time, selective deep lobe parotidectomy preserves the function of the gland ${ }^{12}$. The rates of postsurgical complications in the 2000s-2010s after total, selected superficial parotidectomy, or deep lobe parotidectomy are presented in the Table I. In general, these rates are acceptable. In the 1980s, for example, the rate of temporary facial damage of $28 \%$ was considered low ${ }^{27}$, while today such a rate is considered as high. We can trace some decline in the rates of complications compared to the results of the 1980s ${ }^{27-30}$, but in general this decline is not very impressive. Frey's syndrome (symptomatic gustatory sweating and inflammation of the skin over the site of the parotidectomy) and the facial nerve involvement remain the main unsolved problems, especially in total/radical cases.

I will not discuss the extracapsular dissection complication rate versus traditional superficial parotidectomy approach in this review article, because this technique needs special attention and will be discussed separately in a special article in this salivary disorders issue.

Submandibular sialadenectomy, sublingual sialadenectomy. Submandibular gland excision is traditionally performed using a transcervical approach. In addition to tumours, failure to remove submandibular calculi via minimal invasive methods may also require sialadenectomy. Swelling in the floor of the mouth (ranula, plunging ranula) can occur after submandibular sialadenectomy and may require removal of the sublingual gland as well ${ }^{31}$. Currently, even a transcervical approach to the submandibular gland can be endoscopically-assisted ${ }^{32}$. Submandibular

Table I. Rates of postsurgical complications in current literature in cases of total parotidectomy 7-9 11 13-15 17-21 2325, superficial/partial parotidectomy ${ }^{11} 1315-20222325$, and selected deep lobe parotidectomy 10-12 232426 .

\begin{tabular}{lccc} 
Complications & Total excision & $\begin{array}{c}\text { Deep lobe } \\
\text { excision }\end{array}$ & $\begin{array}{c}\text { Superficial } \\
\text { excision }\end{array}$ \\
$\begin{array}{l}\text { Temporary facial } \\
\text { weakness }\end{array}$ & $41.7 \%-9 \%$ & $26 \%-7 \%$ & $20 \%-9 \%$ \\
$\begin{array}{l}\text { Permanent facial } \\
\text { weakness }\end{array}$ & $9 \%-0 \%$ & $7 \%-0 \%$ & $7 \%-0 \%$ \\
$\begin{array}{l}\text { Post-operative } \\
\text { hematoma }\end{array}$ & $7 \%-0 \%$ & $3 \%-0 \%$ & $3.2 \%-0 \%$ \\
$\begin{array}{l}\text { Frey's syndrome } \\
\text { Salivary fistula }\end{array}$ & $25 \%-1 \%$ & $0 \%$ & $17 \%-1 \%$ \\
$\begin{array}{l}\text { Sialocele } \\
\text { Infection }\end{array}$ & $11 \%-0 \%$ & Not reported & $1.7 \%$ \\
$\begin{array}{l}\text { Sensory deficit } \\
\text { Seroma }\end{array}$ & $16 \%-0 \%$ & $1 \%-0 \%$ & $26 \%-0 \%$ \\
Keloid formation & $1.5 \%-0 \%$ & $1 \%-0 \%$ & $1 \%-0 \%$ \\
Greater auricular & $10.4 \%-0 \%$ & $2 \%-0 \%$ & $3 \%-0 \%$ \\
nerve anaesthesia & & Not reported & Not reported \\
\hline
\end{tabular}


gland excision in malignant cases is followed by subsequent neck dissection or the elective neck dissection because cancers in the submandibular gland are generally more aggressive than the same histologic types in the parotid gland ${ }^{33} 34$. Neck dissection has its own postsurgical complications.

In cases that involve submandibular gland excision, the majority of complications arise because of mistakes in identification of the lingual nerve, the marginal mandibular nerve, and the submandibular duct (rare) ${ }^{35}$. Injuries of the marginal mandibular branch of the facial nerve is the most frequent postsurgical complication that can end with permanent paresis or paralysis in 1-7\% of cases, and lingual nerve injury is the second most frequent nerve damage with a $0.5-4.4 \%$ risk of paralysis ${ }^{35-39}$. This complication may occur because of adhesion or partial adhesion between Wharton's duct and the lingual nerve. If a transoral surgical approach is chosen, specific complications might include oedema at the mouth base, lingual ecchymosis and postoperative temporary abnormal tongue sensation ${ }^{40}$.

Xerostomia and decreased salivary flow in a resting position is a specific long term complication after submandibular sialadenectomy because the submandibular glands are responsible for $70 \%$ of resting salivary flow. Up to $22 \%$ of operated patients can be affected with it ${ }^{37}$. Other complications might include a heterotrophic scar, keloid formation, Frey's syndrome (rare in submandibular cases), and injuries to the submandibular duct, ranula and intraoperative bleeding ${ }^{41}$. The damage to the hypoglossal nerve or to the cervical branch of the facial nerve are possible but very rare ${ }^{3542}$.

Calculi, ranulas and malignant sublingual gland neoplasms are rare. In cases with cancer, wide tumour-free surgical margin excision is the treatment of choice and the above mentioned nerves can be damaged ${ }^{43}$. Injuries of Wharton's duct are also possible, but in general the rate of complications is somewhat lower than in cases of submandibular surgery ${ }^{4144}$. Xerostomia and Frey's syndrome are not observed.

Transoral/intraoral surgical approaches with or without endoscopic assistance are mainly used for removal of salivary stones located in the ducts including giant sialoliths ${ }^{45}$. However, this technique can be applied for removal of hiloparenchymal submandibular calculi as well ${ }^{46}$. In general, authors indicate a very low rate of complications (3\%-0\%), such as functional disorder of the marginal mandibular, hypoglossal and lingual nerves, or wound haematoma formation ${ }^{45-48}$. It should be remembered that these results are mostly limited to cases of sialolithiasis.

\section{Endoscopy-related complications}

While endoscopic and endoscopy-assisted surgeries can have general postsurgical complications such as infection or haematoma ${ }^{49}$, endoscopic interventions may produce several specific complications ${ }^{50}$. A combined or endoscopy-assisted surgical technique is usually applied for removing large sialoliths from the salivary glands or after failure of a pure endoscopic approach. The only contraindication for the endoscopic intervention is acute sialadenitis. The authors agree that most of the sialendoscopy complications are minor, yet some require specific attention ${ }^{49-52}$. Endoscopy-related complications are different origin in comparison with the above described traditional surgery complications, and direct comparison of risks is difficult. While most complications of radical surgery are neurological, these types of complications are minimal when sialendoscopy is used. Facial palsy/paralysis or Frey's syndrome never occur ${ }^{51534}$. Lingual nerve paraesthesia might occur if the submandibular gland is involved, but the risk of complication is minimal $(<0.7 \%)^{5455}$.

Major endoscopy-related complications are defined as iatrogenic insults directly responsible for additional procedures ${ }^{5657}$. The generally accepted definition for minor complications indicate them as events leading to either failure of the procedure, a second surgical procedure, a change in the surgical plan, or deviation from the planned course of events as a result of the procedure itself. Following these definitions, the major complications occur in only $2-3 \%$ of cases, and the minor complications occur in $19-23 \%{ }^{50-58}$. The avulsion of the salivary duct, secondary strictures, gland swelling, salivary fistulas and perforations (false rout), traumatic ranulas, and lingual nerve paraesthesia are the main endoscopy-related complications.

Avulsion of the duct occurs during the removal of a calculus. The surgeon fixes a calculus in the wire basket and then tries to remove it from the duct. If traction efforts are excessive, avulsion can occur. This complication is rare, but is possible if the operation is performed by inexperienced surgeon.

Secondary, or postoperative, strictures of the salivary duct are the main complication following sialendoscopic procedures ${ }^{51-5459}$. The risk for such a complication remains after each operative endoscopic surgery, but does not exceed 2-2.45\% 535960 . Strictures can be identified in both parotid and submandibular cases by continuous swelling of the gland following stone extraction without any evidence of additional or stone particle intraductally, and absence of saliva or reduced saliva secretion from the orifice of the affected gland. Most postoperative strictures are located near the orifice region, and successful dilation is possible in the majority of cases ${ }^{53-5560}$.

The perforation (false rout) of the salivary duct occurs either near the orifice of the duct due to separation of the ductal wall from the oral mucosa or during sialendoscopic mechanical procedures intraductally like stone removal and stricture dilation ${ }^{59-61}$. The endoscopic identification of this pathology is possible, but ductal structures of the lumen can be overlooked. Another sign is the excessive swelling in the region of the perforation due to the leakage of the irrigation solution to surrounding tissue.

Post-operative gland swelling occurs when the main goal of the minimally invasive surgery was achieved, i.e. the gland was preserved. Excessive swelling following si- 
alendosopy usually occurs because of the obstruction of the main salivary duct, peroration of the duct, or excessive irrigation ${ }^{53} 54$. Such gland swelling usually resolves in approximately 24-48 hours ${ }^{5456}$. While generally not hazardous, this complication may cause airway compromise after submandibular surgery ${ }^{63}$. Therefore, if bilateral submandibular intervention is planned, a surgeon should examine the gland and oral cavity after operating the first gland and determine whether it is safe to proceed with the second gland.

Ranula formation is a well documented outcome of surgical procedures in the floor of the mouth. Formation of ranula can occur in patients following submandibular sialendoscopy 55606465 . In submandibular or sublingual endoscopic surgery, the risk is $1-2.45 \%{ }^{64-66}$. The formation of ranula is proportional to the extent of the procedure and patients who underwent endoscopic assisted intervention like stretching procedure have a reasonable risk for this complication. Ranula is easily identified by swelling, mostly blue, in the floor of the oral cavity. Successful marsupialisation occurs in majority of cases.

Lingual nerve paraesthesia is a rare complication of sialendoscopy of the submandibular gland $(0.7 \%-0.4 \%){ }^{5261}$. It can happen mainly in an endoscopic assisted procedure - the stretching technique. During a pure intraductal endoscopic procedure, it can happen only due to perforation of the salivary duct. Usually, the lesion is identified by nerve assessment. Changing paraesthesia into anaesthesia is even rarer. If the nerve is damaged, steroid treatment should be administered immediately after correct diagnosis. The currently analysed cases show that the risk of this complication exists when the stones are located in the posterior third of the main duct $^{5261}$

Salivary fistulas, sialoceles, minor ductal tears, minor haemorrhage and acute masseteric bend, while reported, should be

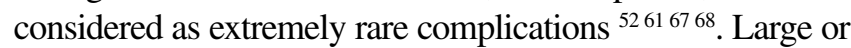
recalcitrant parotid stones can leave a persistent stone fragment or produce obstructive symptoms due to a fibrous stricture that is also very rare. The rates of the postsurgical endoscopy-related complications are presented in Table II.

\section{Complications of the extracorporeal shock-wave lithotripsy}

ESWL delivers 1000-1500 shock waves per session. External lithotripsy is applied with low energy levels up to $130 \mathrm{~atm}$. The lithotripter generates enough power to produce a cavitation effect. The shock waves disconnect the salivary stone from the ductal wall, reduce the volume of the stone and can crush the stone. Due to the low energy levels of the shockwaves, the procedure is not painful and does not require anaesthesia. No specific ESWL-related side effects have been reported ${ }^{265470-73}$.

Sonographic/ultrasonic lithotripsy, however, should be distinguished from laser lithotripsy of salivary stones.
Table II. Rates of the postsurgical endoscopy-related complications in the current literature ${ }^{49-68}$.

\begin{tabular}{lccc}
$\begin{array}{l}\text { Complication } \downarrow \text { / } \\
\text { gland } \rightarrow\end{array}$ & Parotid & Submandibular & Sublingual \\
$\begin{array}{l}\text { Strictures } \\
\text { Ranula }\end{array}$ & $4 \%-2 \%$ & $1 \%-2 \%$ & - \\
$\begin{array}{l}\text { Lingual nerve } \\
\text { paresthesia }\end{array}$ & - & $1.68 \%$ & $0.5 \%$ \\
$\begin{array}{l}\text { Avulsion of the duct } \\
\text { Gland swelling }\end{array}$ & $0.5 \%$ & $0.5 \%-1 \%$ & $0.5 \%$ \\
(temporary) & $5 \%-10 \%$ & $7 \%-12 \%$ & Not reported \\
$\begin{array}{l}\text { Perforation of the } \\
\text { duct }\end{array}$ & $0.5 \%$ & $0.5 \%$ & - \\
\hline
\end{tabular}

Subsequent fragmentation of salivary stones can be performed with a Ho:YAG laser or Er:YAG laser in a near-contact manner, but for this technique damage of salivary duct mucosa, ductal stenosis and salivary fistula are reported as rare complications (less than 2\%) ${ }^{74-76}$. A newly approved pneumatic lithotripter is still under investigation. An intraparenchymal repulsion of a residual fragment of a stone has been reported as a complication ${ }^{77}$. The main problem with the ESWL is not the rate of specific complications, but its inability to fragment all stones and remove all the fragments from the ducts. Total elimination of the stone by lithotripsy alone can be achieved in $30-50 \%$ of cases 2654707178 . The success of the technique is more impressive when ESWL is combined with sialoendoscopic intervention ${ }^{78}$.

\section{Conclusions}

In general, the rate of postsurgical complications after modern advanced minimally invasive surgical interventions is significantly lower compared toe traditional surgery of the salivary glands. However, such a comparison cannot be performed because up-to-date traditional and minimally invasive surgical techniques are currently applied to different salivary disorders.

\section{References}

1 Marmary Y. A novel and non-invasive method for the removal of salivary gland stones. Int J Oral Maxillofac Surg 1986;15:585-7.

2 Iro H, Benzel W, Zenk J, et al. Minimally invasive treatment of sialolithiasis using extracorporeal shock waves. HNO 1993;41:311-6.

3 Katz P. Endoscopy of the salivary glands. Ann Radiol (Paris) 1991;34:110-3.

4 Katz P. New treatment method for salivary lithiasis. Rev Laryngol Otol Rhinol (Bord) 1993;114:379-82.

5 Nahlieli O, Neder A, Baruchin AM. Salivary gland endoscopy: a new technique for diagnosis and treatment of sialolithiasis. J Oral Maxillofac Surg 1994;52:1240-2.

6 Iro H, Zenk J, Waldfahrer F, et al. Extracorporeal shock wave 
lithotripsy of parotid stones. Results of a prospective clinical trial. Ann Otol Rhinol Laryngol 1998;107:860-4.

7 Eviston TJ, Yabe TE, Gupta R, et al. Parotidectomy: surgery in evolution. ANZ J Surg 2016;86:193-9.

8 Mantsopoulos K, Koch M, Klintworth N, et al. Evolution and changing trends in surgery for benign parotid tumors. Laryngoscope 2015;125:122-7

9 Leverstein H, Van der Wal JE, Tiwari RM, et al. Results of the surgical management and histopathological evaluation of 88 parotid gland Warthin's tumours. Clin Otolaryngol Allied Sci 1997;22:500-3.

${ }_{10}$ Hussain A, Murray DP. Preservation of the superficial lobe for deep-lobe parotid tumors: a better aesthetic outcome. Ear Nose Throat J 2005;84:518,520-2,524.

11 Ikoma R, Ishitoya J, Sakuma Y, et al. Temporary facial nerve dysfunction after parotidectomy correlates with tumor location. Auris Nasus Larynx 2014;41:479-84.

12 Colella G, Giudice A, Rambaldi P, et al. Parotid function after selective deep lobe parotidectomy. Br J Oral Maxillofac Surg 2007;45:108-11.

13 Thahim K, Udaipurwala IH, Kaleem M. Clinical manifestations, treatment outcome and post-operative complications of parotid gland tumours - an experience of 20 cases. J Pak Med Assoc 2013;63:1472-5.

14 Thom JJ, Moore EJ, Price DL, et al. The role of total parotidectomy for metastatic cutaneous squamous cell carcinoma and malignant melanoma. JAMA Otolaryngol Head Neck Surg 2014;140:548-54.

15 Kim BD, Lim S, Wood J, et al. Predictors of adverse events after parotidectomy: a review of 2919 cases. Ann Otol Rhinol Laryngol 2015;124:35-44.

16 Plaza G, Amarillo E, Hernández-García E, et al. The role of partial parotidectomy for benign parotid tumors: a case-control study. Acta Otolaryngol 2015;135:718-21.

17 El Fol HA, Beheiri MJ, Zaqri WA. Comparison of the effect of total conservative parotidectomy versus superficial parotidectomy in management of benign parotid gland tumor: A systematic review. J Craniomaxillofac Surg 2015. pii: S10105182(15)00012-8.

18 Derin S, Erdogan S, Almac A, et al. Parotid gland tumours in Turkish population: analysis of 165 patients. Asian Pac J Cancer Prev 2015;16:3539-42.

19 Maahs GS, Oppermann Pde O, Maahs LG, et al. Parotid gland tumors: a retrospective study of 154 patients. Braz $\mathrm{J}$ Otorhinolaryngol 2015;81:301-6.

20 Achour I, Chakroun A, Ben Rhaiem Z, et al. Surgery of pleomorphic adenoma of the parotid gland. Rev Stomatol Chir Maxillofac Chir Orale 2015;116:129-31.

21 Renkonen S, Sayed F, Keski-Säntti H, et al. Reconstruction of facial nerve after radical parotidectomy. Acta Otolaryngol.2015;135:1065-9.

22 Yuen AP. Small access postaural parotidectomy: an analysis of techniques, feasibility and safety. Eur Arch Otorhinolaryngol 2016;273:1879-83.

23 Vaiman M, Jabarin B, Abuita R. Methylene blue staining in the parotid surgery: Randomized trial, 144 patients. Am J Otolaryngol 2016;37:22-6.

${ }^{24}$ Vaiman M, Abuita R, Jabarin B. Selective deep lobe parotid surgery for benign tumors. Acta Otolaryngol 2015;135:1319-22.

25 Correia-Sá IB, Correia-Sá M, Costa-Ferreira P, et al. Eleven years of parotid gland surgery in a plastic and reconstructive department. J Craniofac Surg 2016;27:e26-33.

${ }_{26}$ Olsen KD, Moore EJ. Deep lobe parotidectomy: clinical rationale in the management of primary and metastatic cancer. Eur Arch Otorhinolaryngol 2014; 271:1181-5.

27 Brusati R, Bozzetti A, Chiapasco M. Facial nerve and parotid surgery. J Craniomaxillofac Surg 1987;15:278-80.

28 Singleton GT, Cassisi NJ. Frey's syndrome: incidence related to skin flap thickness in parotidectomy. Laryngoscope 1980;90(10 Pt 1):1636-9.

29 Martis C. Parotid benign tumors: comments on surgical treatment of 263 cases. Int J Oral Surg 1983;12:211-20.

30 Powell ME, Clairmont AA. Complications of parotidectomy. South Med J 1983;76:1109-12.

31 O'Regan B, Mather CI. Ipsilateral removal of sublingual gland after excision of submandibular gland for benign disease: 10-year prospective study and comprehensive review 1978-2008. Br J Oral Maxillofac Surg 2011;49:186-9.

32 Hamza Y, Khalil R. Video-assisted submandibular resection: two-step technique. Surg Endosc 2009;23:2785-9.

33 Silver NL, Chinn SB, Bradley PJ, et al. Surgery for malignant submandibular gland neoplasms. Adv Otorhinolaryngol 2016;78:104-12.

34 Nobis CP, Rohleder NH, Wolff KD, et al. Head and neck salivary gland carcinomas - elective neck dissection, yes or no? J Oral Maxillofac Surg 2014;72:205-10.

35 Nocon CC, Cohen MA, Langerman AJ. Quality of neck dissection operative reports. Am J Otolaryngol 2016;37:330-3.

36 de Carvalho AS, Dedivitis RA, de Castro MA, et al. Submandibular gland excision. Rev Col Bras Cir 2015;42:14-7.

37 Springborg LK, Møller MN. Submandibular gland excision: long-term clinical outcome in 139 patients operated in a single institution. Eur Arch Otorhinolaryngol 2013;270:1441-6.

38 Delsing CP, Cillessen E, Scheffer A, et al. Bilateral submandibular gland excision for drooling: our experience in twenty-six children and adolescents. Clin Otolaryngol 2015;40:285-90.

39 Preuss SF, Klussmann JP, Wittekindt C, et al. Submandibular gland excision: 15 years of experience. $\mathrm{J}$ Oral Maxillofac Surg 2007;65:953-7.

40 Akbay E, Cevik C, Arli C. Perioperative difficulties and early postoperative complications of transoral approach in mouth base surgery. J Craniofac Surg 2014;25:e143-8.

${ }^{41}$ Zhao GR, Ji P, Zhao HW, et al. Modified L-shaped surgical approach to excision of the sublingual gland. Br J Oral Maxillofac Surg 2015;53:725-9.

42 Righini CA, Petrossi J, Reyt E, et al. An original submandibular approach technique sparing the cervical branch of the facial nerve. Eur Ann Otorhinolaryngol Head Neck Dis 2014;131:143-6.

43 Bradley PJ, Ferris RL. Surgery for malignant sublingual and minor salivary gland neoplasms. Adv Otorhinolaryngol 2016;78:113-9.

${ }^{44}$ Chakravarti A, Gupta R, Garg S, et al. Bilateral submandibular duct transposition with sublingual gland excision 
for cerebral palsy children with drooling. Indian J Pediatr 2014;81:623-4.

45 Boffano P, Gallesio C. Surgical treatment of a giant sialolith of the Wharton duct. J Craniofac Surg 2010;21:134-5.

46 Capaccio P, Clemente IA, McGurk M, et al. Transoral removal of hiloparenchymal submandibular calculi: $a$ long-term clinical experience. Eur Arch Otorhinolaryngol 2011;268:1081-6.

47 Komatsuzaki Y, Ochi K, Sugiura N, et al. Video-assisted submandibular sialadenectomy using an ultrasonic scalpel. Auris Nasus Larynx 2003;30(Suppl):S75-8.

48 Combes J, Karavidas K, McGurk M. Intraoral removal of proximal submandibular stones - an alternative to sialadenectomy? Int J Oral Maxillofac Surg 2009;38:813-6.

49 Parente Arias PL, Fernández Fernández MM, Varela Vázquez $\mathrm{P}$, et al. Minimally invasive video-assisted submandibular sialadenectomy: surgical technique and results from two institutions. Surg Endosc 2016;30:3314-20.

50 Pitak-Arnnop P, Pausch NC, Dhanuthai K, et al. Endoscope-assisted submandibular sialadenectomy: a review of outcomes, complications, and ethical concerns. Eplasty 2010;10:e36.

51 Lari N, Chossegros C, Thiery G, et al. Sialendoscopy of the salivary glands. Rev Stomatol Chir Maxillofac 2008;109:167-71.

52 Strychowsky JE, Sommer DD, Gupta MK, et al. Sialendoscopy for the management of obstructive salivary gland disease: a systematic review and meta-analysis. Arch Otolaryngol Head Neck Surg 2012;138:541-7.

${ }_{53}$ Marchal F, Becker M, Dulguerov $\mathrm{P}$, et al. Interventional sialendoscopy. Laryngoscope 2000;110:318-320.

${ }_{54}$ Nahlieli O. Advanced sialoendoscopy techniques, rare findings, and complications. Otolaryngol Clin North Am 2009;42:1053-72.

55 Iro H, Zenk J, Escudier MP, Nahlieli O, et al. Outcome of minimally invasive management of salivary calculi in 4,691 patients. Laryngoscope 2009;119:263-8.

56 Bowen MA, Tauzin M, Kluka EA, et al. Diagnostic and interventional sialendoscopy: a preliminary experience. Laryngoscope 2010;121:299-303.

57 Walvekar RR, Razfar A, Carrau RL, et al. Sialendosocopy and associated complications: a preliminary experience. Laryngoscope 2008;118:776-9.

58 Nahlieli O, Nakar LH, Nazarian Y, et al. Sialoendoscopy: a new approach to salivary gland obstructive pathology. J Am Dent Assoc 2006;137:1394-400.

59 Marchal F, Chossegros C, Faure F, et al. Salivary stones and stenosis. A comprehensive classification. Rev Stomatol Chir Maxillofac 2008;109:233-6.

${ }^{60}$ Nahlieli O, Bar T, Shacham R, et al. Management of chronic recurrent parotitis: current therapy. J Oral Maxillofac Surg 2004;62:1150-5.

${ }^{61}$ Atienza G, López-Cedrún JL. Management of obstructive salivary disorders by sialendoscopy: a systematic review. $\mathrm{Br}$ J Oral Maxillofac Surg 2015;53:507-19.

62 Kroll T, Finkensieper M, Sharma SJ, et al. Short-term outcome and patient satisfaction after sialendoscopy. Eur Arch Otorhinolaryngol 2013;270:2939-45.

63 Iwai T, Matsui Y, Yamagishi M, et al. Simple technique for dilatation of the papilla in sialoendoscopy. J Oral Maxillofac Surg 2009;67:681-2.

${ }^{64}$ Nahlieli O, Droma EB, Eliav E, et al. Salivary gland injury subsequent to implant surgery. Int J Oral Maxillofac Implants 2008;23:556-60.

65 Mandel L. Plunging ranula following placement of mandibular implants: case report. J Oral Maxillofac Surg 2008;66:1743-7.

${ }^{66}$ Harrison JD, Kim A, Al-Ali S, et al. Postmortem investigation of mylohyoid hiatus and hernia: aetiological factors of plunging ranula. Clin Anat 2013;26:693-9.

67 Gary C, Kluka EA, Schaitkin B, et al. Interventional sialendoscopy for treatment of juvenile recurrent parotitis. J Indian Assoc Pediatr Surg 2011;16:132-6.

68 Al-Abri R, Marchal F. New era of endoscopic approach for sialolithiasis: sialendoscopy. Sultan Qaboos Univ Med J 2010;10:382-7.

69 Karavidas K, Nahlieli O, Fritsch M, et al. Minimal surgery for parotid stones: a 7-year endoscopic experience. Int J Oral Maxillofac Surg 2010;39:1-4.

70 Zenk J, Koch M, Iro H. Extracorporeal and intracorporeal lithotripsy of salivary gland stones: basic investigations. Otolaryngol Clin North Am 2009;42:1115-37.

71 Zenk J, Koch M, Mantsopoulos K, et al. The significance of extracorporeal shock wave lithotripsy in sialolithiasis therapy. HNO 2013;61:306-11.

72 Abdusalamov MR, Afanas'ev VV, Gamataev II. Shockwave lithotripsy in sialolithiasis patients. Stomatologiia (Mosk) 2014;93:31-2.

73 Desmots F, Chossegros C, Salles F, et al. Lithotripsy for salivary stones with prospective US assessment on our first 25 consecutive patients. J Craniomaxillofac Surg 2014;42:577-82.

74 Raif J, Vardi M, Nahlieli O, et al. An Er:YAG laser endoscopic fiber delivery system for lithotripsy of salivary stones. Lasers Surg Med 2006;38:580-7.

75 Schrötzlmair F, Müller M, Pongratz T, et al. Laser lithotripsy of salivary stones: Correlation with physical and radiological parameters. Lasers Surg Med 2015;47:342-9.

76 Martellucci S, Pagliuca G, de Vincentiis M, et al. Ho:Yag laser for sialolithiasis of Wharton's duct. Otolaryngol Head Neck Surg 2013;148:770-4.

77 Koch M, Mantsopoulos K, Schapher M, et al. Intraductal pneumatic lithotripsy for salivary stones with the StoneBreaker: Preliminary experience. Laryngoscope 2016;126:1545-50.

78 Nahlieli O, Shacham R, Zaguri A. Combined external lithotripsy and endoscopic techniques for advanced sialolithiasis cases. J Oral Maxillofac Surg 2010;68:347-53.

Received: September 15, 2016 - Accepted: December 12, 2016

Address for correspondence: Oded Nahlieli, Department of Oral and Maxillofacial Surgery Barzilai Medical Center Ashkelon, 78306, Israel. E-mail: nahlieli@yahoo.com 